Abstract SAT0461 - Table 1. Proportion of patients with residual disease at Week 24

\begin{tabular}{|c|c|c|c|c|c|c|}
\hline & MDA 5/7, n/N (\%) & MDA_skin, n/N (\%) & MDA_joint, n/N (\%) & MDA_joint + skin, n/N (\%) & DAPSA LDA, n/N (\%) & cDAPSA LDA, n/N (\%) \\
\hline Dactylitis (1-12) & 10/322 (3) & $6 / 131(5)$ & $5 / 255(2)$ & 3/97 (3) & $18 / 475(4)$ & $17 / 478(4)$ \\
\hline Enthesitis (1-5) & $2 / 324$ (1) & 2/132 (2) & $1 / 256(0)$ & $1 / 97(1)$ & $16 / 477$ (3) & $16 / 480(3)$ \\
\hline PASI (2-9) & $142 / 324(44)$ & $0 / 132(0)$ & $119 / 256(47)$ & 0/97 (0) & $237 / 477(50)$ & $237 / 480$ (49) \\
\hline PASI $(\geq 10)$ & $17 / 324(5)$ & $0 / 132(0)$ & $14 / 256(6)$ & $0 / 97(0)$ & r 38/477 (8) & $39 / 480(8)$ \\
\hline $\mathrm{TJC}(>1)$ & $46 / 324(14)$ & $28 / 132(21)$ & $0 / 256(0)$ & $0 / 97(0)$ & $140 / 477(29)$ & $139 / 480(29)$ \\
\hline $\operatorname{SJC}(>1)$ & $25 / 324(8)$ & 15/132 (11) & $0 / 256(0)$ & 0/97 (0) & $65 / 477$ (14) & $65 / 480(14)$ \\
\hline
\end{tabular}

cut-offs were met but some were mandated: MDA_joint with both TJC and SJC cut-offs mandated, MDA_skin where PASI cut-off was mandated, MDA_joint+skin where the TJC, SJC, and skin cut-offs were mandated.

Results: At Week 24, the proportion of patients achieving LDA were $47 \%, 20 \%$, $38 \%, 14 \%$ in MDA 5/7, MDA skin, MDA joint, MDA joint+skin, respectively, vs $\sim 71 \%$ in DAPSA and cDAPSA LDA. The highest proportion of discordance was observed between MDA_skin or MDA_joint+skin with DAPSA LDA or cDAPSA LDA (Figure). The majority of patients had no residual arthritis although levels were highest in the DAPSA measurements (Table). However, notable residual levels of psoriasis were observed in measurements that did not require skin disease control (Table 1). MDA joint+skin had the lowest levels of residual disease across all cut-offs (Table 1$)$. At Week 12, a significant difference $(P<0.05)$ between the $50 \mathrm{mg}$ etanercept (ETN) once a week and $50 \mathrm{mg}$ ETN twice a week cohorts was observed in the measurements that required a skin cut-off (MDA skin and MDA joint+skin) and MDA 5/7 but not in DAPSA LDA, CDAPSA LDA, or MDA joint.

Figure. Proportion with discordance for DAPSA LDA or CDAPSA LDA across different low disease activity definitions at Week 24

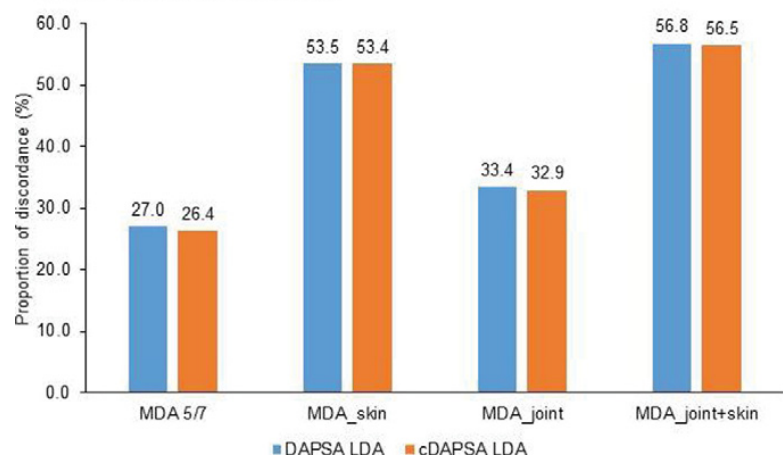

Conclusions: DAPSA and CDAPSA LDA provided the least stringent cut-offs with the highest percentages of patients with residual disease. Whilst choosing the optimal target for treatment requires more debate, it is clear from these data that levels of residual psoriasis are high in those measurements that do not require skin control. If this is not included in a treatment target for PsA, notable levels of psoriasis can be missed.

References:

[1] Sterry W, et al. BMJ 2010;340:c1471.

Disclosure of Interest: L. Coates Grant/research support from: Abbvie, Janssen, Consultant for: Abbvie, BMS, Janssen, Lilly, MSD, Novartis, Pfizer, A. Gottlieb Grant/research support from: Centocor (Janssen), Amgen, Abbvie, Novartis, Celgene, Pfizer, Lilly, Levia, Merck, Xenoport, Dermira, Baxalta, Consultant for: Amgen, Astellas, Akros, Centocor (Janssen), Celgene, Bristol Myers Squibb, Beiersdorf, Abbvie, TEVA, Actelion, UCB, Novo Nordisk, Novartis, Dermipsor, Incyte, Pfizer, Canfite, Lilly, Coronado, Vertex, Karyopharm, CSL Behring Biotherapies for Life, Glaxo Smith Kline, Xenoport, Catabasis, Meiji Seika Pharma, Takeda, Mitsubishi,Tanabe Pharma Development America, Genentech, Baxalta, Kineta One, KPI Therapeutics, Crescendo Bioscience, Aclaris, Amicus, Reddy Labs, Speakers bureau: Abbvie, J. Merola Consultant for: Biogen IDEC, AbbVie, Amgen, Eli Lilly, Novartis, Pfizer, Janssen, UCB, Kiniksa, Momenta and Mallinckrodt, L. Aikman Shareholder of: Pfizer, Employee of: Pfizer, A. Szumski Employee of: InVentiv Health, A. Chhabra Shareholder of: Pfizer, Employee of: Pfizer DOI: 10.1136/annrheumdis-2017-eular.1874

\section{SAT0462 SECUKINUMAB PROVIDES SUSTAINED PASDAS RELATED LOW DISEASE ACTIVITY IN PSORIATIC ARTHRITIS: 2 YEAR RESULTS FROM THE FUTURE 2 STUDY}

L.C. Coates ${ }^{1,2}$, D.D. Gladman ${ }^{3}$, P. Nash ${ }^{4}$, O. Fitzgerald ${ }^{5}$, A. Kavanaugh ${ }^{6}$, L. Rasouliyan ${ }^{7}$, L. Pricorp ${ }^{8}$, K. Ding ${ }^{8}$, C. Gaillez ${ }^{9}$ on behalf of the FUTURE 2 study group. ${ }^{1}$ Leeds Teaching Hospitals NHS Trust; ${ }^{2}$ University of Leeds, Leeds, United Kingdom; ${ }^{3}$ Toronto western hospital, Toronto, Canada; ${ }^{4}$ University of Queensland, Brisbane, Australia; ${ }^{5}$ University College Dublin, Dublin, Ireland; ${ }^{6}$ UC San Diego School of Medicine, la Jolla, United States: ${ }^{7}$ RTI Health Solutions, Barcelona, Spain; ${ }^{8}$ Novartis Pharmaceuticals Corporation, East Hanover, United States; ${ }^{9}$ Novartis Pharma AG, Basel, Switzerland

Background: Psoriatic arthritis (PsA) disease activity score (PASDAS) assessing multiple facets of PsA was demonstrated to distinguish treatment effect, perform better in statistical terms than traditional joint-only indices ${ }^{1}$ and could be used as a treatment target in clinical trials in PsA.

Objectives: Secukinumab provided sustained improvement in the signs and symptoms of PsA over 104 weeks (wks) in the FUTURE 2 study. ${ }^{2}$ Here, we report the ability of secukinumab to reach and sustain PASDAS based low disease activity (LDA) up to 104 wks in the FUTURE 2 study using a post-hoc exploratory analysis.

Methods: 397 patients (pts) with active PsA were randomised to subcutaneous (s.c.) secukinumab (300mg, 150mg, or $75 \mathrm{mg}$ ) or placebo (PBO) at baseline (BL) Wks 1,2 , and 3 , and every 4 wks $(q 4 w)$ from Wk 4 . PBO nonresponder and responder pts were re-randomised to secukinumab 300 or $150 \mathrm{mg}$ s.c. q4w from Wk 16 and 24, respectively. PASDAS is derived from physician's global VAS, patient's global VAS, SF-36 PCS, tender and swollen joints (TJC 68 and SJC 66), Leeds enthesitis count, dactylitis count and CRP level and has cut-points for high disease activity $(H D A \geq 5.4)$, low disease activity $(\operatorname{LAA}<3.2)$ and remission $(\mathrm{REM}<1.9) .^{3}$ PASDAS was assessed in the overall population and in pts stratified by prior anti-TNF use (naïve/inadequate response [IR]) and disease duration ( $\leq 2$ years vs. $>2$ years since diagnosis) and reported using non-mutually exclusive categories at group level and as observed analysis. Secukinumab $75 \mathrm{mg}$ data are not reported as this was not considered an effective dose. ${ }^{2}$

Results: PASDAS score (mean [SD]) at baseline was $5.9(0.9), 6.0$ (1.0) and 5.8 (1.0) in the secukinumab $300 \mathrm{mg}, 150 \mathrm{mg}$ and PBO groups. In the overall population at Wk 16, PASDAS LDA was achieved in $37 / 96$ (38.5\%) and 34/99 $(34.3 \%)$ of pts, treated with secukinumab $300 \mathrm{mg}$ and $150 \mathrm{mg}$, respectively; vs. $14 / 87(16.1 \%)$ with PBO. A high proportion of pts treated with secukinumab 300 and $150 \mathrm{mg}$ achieved LDA (49/83 [59.0\%] and 38/77 [49.4\%], respectively) at Wk 104. The proportion of pts achieving PASDAS LDA and remaining in HDA at Wks 16 and 104 by anti-TNF $\alpha$ status and by disease duration ( $\leq 2$ years vs. $>2$ years) for secukinumab 300 and $150 \mathrm{mg}$ is reported in the figure.
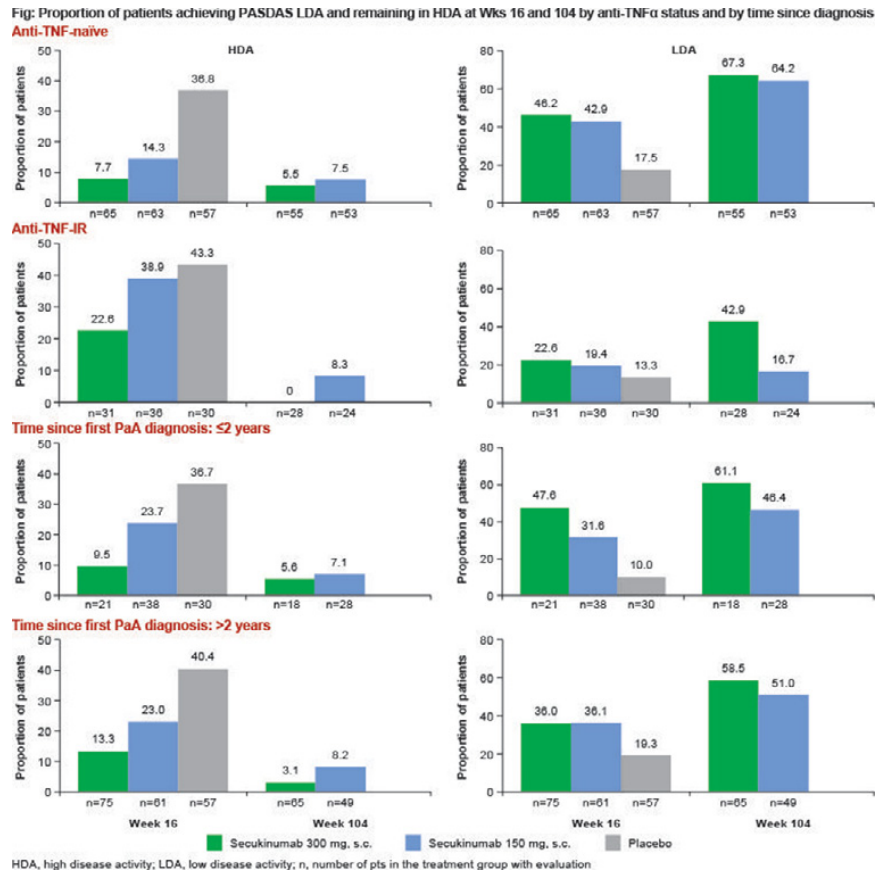

Conclusions: A higher proportion of secukinumab-treated pts at Wk 16 achieved PASDAS LDA than PBO, with LDA sustained at group level at Wk 104. Discriminatory effect of PASDAS was consistent with that previously reported in the GRACE project. ${ }^{4}$ A higher proportion of anti-TNF $\alpha$-naïve pts treated with secukinumab achieved and sustained PASDAS LDA than anti-TNF $\alpha$-IR pts whereas similar proportion of pts treated with secukinumab achieved PASDAS LDA irrespective of time since diagnosis ( $\leq 2$ years vs. $>2$ years).

References:

[1] Helliwell PS and Kavanaugh A. Arth Care and Res. 2014;66:749-56.

[2] McInnes IB et al, Arthritis Rheumatol. 2016;68 (suppl 10).

[3] Coates LC and Helliwell PS, J Rheumatol. 2016;43:371-5. 
[4] Helliwell PS et al, Ann Rheum Dis. 2013;72:986-91.

Disclosure of Interest: L. Coates Grant/research support from: Abbvie, Janssen, Consultant for: Abbvie, BMS, Celgene, Pfizer, UCB, MSD, Novartis, Lilly, Janssen, Sun Pharma, D. Gladman Grant/research support from: Amgen, AbbVie, BMS, Celgene, Eli Lilly, Janssen, Novartis, Pfizer and UCB, P. Nash Grant/research support from: Novartis, Abbvie, Roche, Pfizer, BMS, Janssen, and Celgene, Consultant for: Novartis, Abbvie, Roche, Pfizer, BMS, Janssen, and Celgene, Speakers bureau: Novartis, Abbvie, Roche, Pfizer, BMS, Janssen, and Celgene, O. Fitzgerald Grant/research support from: Bristol-Myers Squibb, Roche, Abbott, Consultant for: Bristol-Myers Squibb, Roche, Abbott, A. Kavanaugh Consultant for: Novartis, L. Rasouliyan Consultant for: Novartis through employment at RTI Health Solutions, Employee of: RTI Health Solutions, L. Pricorp Shareholder of: Novartis, Employee of: Novartis, K. Ding Shareholder of: Novartis, Employee of: Novartis, C. Gaillez Shareholder of: Novartis, BMS, Employee of: Novartis DOI: 10.1136/annrheumdis-2017-eular.1458

\section{SAT0463 SECUKINUMAB PROVIDES SUSTAINED REDUCTION IN FATIGUE IN PATIENTS WITH ACTIVE PSORIATIC ARTHRITIS THROUGH 3 YEARS: LONG-TERM DATA FROM THE FUTURE 1 AND FUTURE 2 STUDIES}

L. Gossec ${ }^{1}$, T.K. Kvien ${ }^{2}$, P.G. Conaghan ${ }^{3}$, M. Østergaard ${ }^{4}$, D. Gladman ${ }^{5}$ P. Mease ${ }^{6}$, L. Rasouliyan 7 , L. Pricop ${ }^{8}$, C. Gaillez ${ }^{9}$, S. Jugl ${ }^{9} .{ }^{1}$ UPMC University Paris 06, Paris, France; ${ }^{2}$ Diakonhjemmet Hospital, Oslo, Norway; ${ }^{3}$ University of Leeds, Leeds, United Kingdom; ${ }^{4}$ Copenhagen Center for Arthritis Research (COPECARE), Glostrup, Denmark; ${ }^{5}$ University of Toronto, Toronto, Canada; ${ }^{6}$ Swedish Medical Center, Seattle, WA, United States: ${ }^{7} R T I$ Health Solutions, Barcelona, Spain; ${ }^{8}$ Novartis Pharmaceuticals Corporation, East Hanover, NJ, United States; ${ }^{9}$ Novartis Pharma AG, Basel, Switzerland

Background: Fatigue, a common symptom in patients (pts) with PsA, can negatively impact HRQoL and social functioning. Secukinumab (SEC), a fully human anti-IL-17A mAb, rapidly improved signs and symptoms, physical functioning, HRQoL, and fatigue in pts with PsA. ${ }^{1,2}$

Objectives: To assess the long-term effects of SEC on fatigue in TNF inhibitor (TNF)-naïve PsA pts and those with an inadequate response or intolerance to TNF inhibitor therapy (TNF-IR).

Methods: 606 and 397 pts were randomized to SEC or placebo (PBO) in FUTURE 1 (10 mg/kg IV followed by 150 or $75 \mathrm{mg} \mathrm{SC}$ ) and FUTURE 2 (300, 150 , or $75 \mathrm{mg} \mathrm{SC}$ ), respectively. At Wk $16, \mathrm{PBO}$ pts with $\leq 20 \%$ reduction in tender/swollen joint count (non-responders) were re-randomized to SEC 150 or $75 \mathrm{mg} \mathrm{SC}$ (FUTURE 1) and SEC 300 or $150 \mathrm{mg} \mathrm{SC} \mathrm{(FUTURE} \mathrm{2);} \mathrm{responders}$ were re-randomized at Wk 24. Pts in FUTURE 1 could enter a LTE study at Wk 104 (NCT01892436). Across both studies, approximately 68\% of pts were TNF-naïve and $32 \%$ were TNF-IR. Fatigue was assessed at baseline (BL) and Wks 4, 8, 12, 16, 24, 52, 104, and 156 (FUTURE 1 only) using FACIT-F (higher scores $=$ less fatigue). Fatigue response was defined by an increase in FACIT-F score of $\geq 4$ from $B L$ (corresponding to the $M C I D$ ). Correlations between $B L$ characteristics and improvements in fatigue were investigated using a logistical regression model. Only data with approved doses of SEC (300/150 mg) are shown.

Results: FACIT-F was 27.8-28.9 and 26.6-29.2 at BL across groups in FUTURE 1 and 2, respectively. Improvements in fatigue seen with all doses of SEC vs. PBO from Wks 4-24 were sustained through 156 wks in FUTURE 1 and 104 wks in FUTURE 2 in both the overall population and subgroups stratified by prior exposure to TNF (Table). The numerically higher responses with SEC 150 vs. $300 \mathrm{mg}$ in this observed analysis were as a result of a higher rate of discontinuation due to lack of efficacy with the lower dose, which inflated the response rate. In the overall population, the LS mean change ( \pm SEM) from $B L$ in FACIT-F was significantly greater with SEC vs. PBO at Wk 16 in both FUTURE 1 ( $7.25 \pm 0.72$ vs. $4.07 \pm 0.76 ; P=0.002)$ and FUTURE 2 (300 mg: $5.89 \pm 0.92$ vs. $1.86 \pm 0.93, P=0.002 ; 150 \mathrm{mg}: 7.40 \pm 0.90$ vs. $1.86 \pm 0.93, P<0.0001)$; improvements were sustained throughout the entire follow up in both studies (FUTURE 1 Wk 156: 6.14 0.77; FUTURE 2 Wk 104: $300 \mathrm{mg} 7.29 \pm 1.04,150 \mathrm{mg} 7.02 \pm 1.06$ ). Improvements were generally somewhat larger in TNF-naïve pts than in TNF-IR pts. Correlation analyses did not identify any BL factors that consistently predicted change in fatigue score across Wks 16, 52, and 104.

Conclusions: SEC-treated PSA pts achieved rapid, sustained, and clinically meaningful improvements in fatigue for up to $156 \mathrm{wks}$, with higher responses in TNF-naïve pts.

References:

[1] McInnes et al. Lancet 2015;386:1137-46.

[2] Mease et al. N Engl J Med 2015;373:1329-39.

Disclosure of Interest: L. Gossec Grant/research support from: BMS, Lippy, Pfizer; Consultant for: Abbvie, BMS, Celgene, Janssen, MSD, Novartis, Pfizer, Roche and UCB, T. Kvien Consultant for: AbbVie, Biogen, BMS, Boehringer Ingelheim, Celltrion, Eli Lilly, Epirus, Janssen, Merck-Serono, MSD, Mundipharma, Novartis, Oktal, Orion Pharma, Hospira/Pfizer, Roche, Sandoz and UCB, Speakers bureau: AbbVie, Biogen, BMS, Boehringer Ingelheim, Celltrion, Eli Lilly, Epirus, Janssen, Merck-Serono, MSD, Mundipharma, Novartis, Oktal, Orion Pharma, Hospira/Pfizer, Roche, Sandoz and UCB, P. Conaghan Consultant for: Abbvie, BMS, Lilly, Novartis, Pfizer, Roche, Speakers bureau: Abbvie, BMS, Lilly, Novartis, Pfizer, Roche, M. Østergaard Consultant for: Abbvie, BMS, Boehringer-Ingelheim,
Table. FACIT-Fatigue responders in FUTURE 1/FUTURE 2 until Week 156/104"

\begin{tabular}{|c|c|c|c|}
\hline \multirow{2}{*}{$\begin{array}{l}\text { Proportion of Patients with FACIT. } \\
\text { Fatigue Response }{ }^{6}, \%(n / m)\end{array}$} & \multirow{2}{*}{$\begin{array}{c}\text { FUTURE } 1^{\circ} \\
\text { SEC IV-150 } \mathrm{mg}\end{array}$} & \multicolumn{2}{|c|}{ FUTURE 2} \\
\hline & & SEC $300 \mathrm{mg}$ & SEC $150 \mathrm{mg}$ \\
\hline Overall Population & $\mathrm{N}=161$ & $N=100$ & $N=100$ \\
\hline Woek 16 & $60.4(96 / 159)$ & $50.5(48 / 95)$ & $70.0(70 / 100)$ \\
\hline Week 52 & $66.9(107 / 160)$ & $60.2(56 / 93)$ & $68.5(61 / 89)$ \\
\hline Week 104 & $63.4(90 / 142)$ & $62.4(53 / 85)$ & $70.1(54 / 77)$ \\
\hline Week 156 & $57.4(89 / 155)$ & - & - \\
\hline TNF-naive & $N=120$ & $\mathrm{~N}=67$ & $\mathrm{~N}=63$ \\
\hline Week 16 & $61.3(73 / 119)$ & $52.4(33 / 63)$ & $71.4(45 / 63)$ \\
\hline Wook 52 & $69.2(83 / 120)$ & $60.7(37 / 61)$ & $72.9(43 / 59)$ \\
\hline Week 104 & $63.9(69 / 108)$ & $60.7(34 / 56)$ & $71.7(38 / 53)$ \\
\hline Week 156 & $58.3(67 / 115)$ & - & - \\
\hline TNF $-\| R$ & $N=41$ & $\mathrm{~N}=33$ & $N=37$ \\
\hline Week 16 & $57.5(23 / 40)$ & $46.9(15 / 32)$ & $67.6(25 / 37)$ \\
\hline Woek 52 & $60.0(24 / 40)$ & $59.4(19 / 32)$ & $60.0(18 / 30)$ \\
\hline Woek 104 & $61.8(21 / 34)$ & $65.5(19 / 29)$ & $66.7(16 / 24)$ \\
\hline Week 156 & $55.0(22 / 40)$ & - & - \\
\hline
\end{tabular}

"Observed data are shown; ${ }^{b}$ Defined as improvement 24.0 points: "Data shown are from patients who entered the FUTURE 1 long-term extension study at Week 104 $\mathrm{m}$, number of patients with sufficient data for evaluation; $\mathrm{N}$, number of patients randomized to SEC $150 \mathrm{mg}$ or SEC $300 \mathrm{mg}$ (FUTURE 2 only); $n$, number of responders.

Celgene, Eli-Lilly, Janssen, Merck, Novartis, Orion, Pfizer, Regeneron, Roche, UCB, Speakers bureau: Abbvie, BMS, Boehringer-Ingelheim, Celgene, Eli-Lilly, Janssen, Merck, Novartis, Orion, Pfizer, Regeneron, Roche, UCB, D. Gladman Grant/research support from: Abbvie, Amgen, BMS, Celgene, Eli Lilly, Janssen, Novartis, Pfizer, UCB, Consultant for: Abbvie, Amgen, BMS, Celgene, Eli Lilly, Janssen, Novartis, Pfizer, UCB, P. Mease Grant/research support from: Abbvie, Amgen, BMS, Boehringer-Ingelheim, Celgene, Eli-Lilly, Janssen, Merch, Novartis, Pfizer, SUN, UCB, Consultant for: Abbvie, Amgen, BMS, Boehringer-Ingelheim, Celgene, Eli-Lilly, Janssen, Merch, Novartis, Pfizer, SUN, UCB, Speakers bureau: Abbvie, Amgen, BMS, Boehringer-Ingelheim, Celgene, Eli-Lilly, Janssen, Merch, Novartis, Pfizer, SUN, UCB, L. Rasouliyan Consultant for: Novartis, L. Pricop Shareholder of: Novartis, Employee of: Novartis, C. Gaillez Shareholder of: Novartis and BMS, Employee of: Novartis, S. Jugl Shareholder of: Novartis, Employee of: Novartis

DOI: 10.1136/annrheumdis-2017-eular.1719

\section{SAT0464 THE IDEAL TARGET FOR PSORIATIC ARTHRITIS? COMPARISON OF REMISSION AND INACTIVE DISEASE STATES IN A REAL LIFE COHORT}

L.J.J. Van Mens ${ }^{1}$, A.W.R. van Kuijk ${ }^{2}$, D.L. Baeten ${ }^{1,3}$, L.C. Coates ${ }^{4} .{ }^{1}$ AMC; ${ }^{2}$ Reade, Amsterdam Immunology and Rheumatology Center, Amsterdam, Netherlands; ${ }^{3}$ UCB, Brussels, Belgium; ${ }^{4}$ LIRMM, University of Leeds, Leeds, United Kingdom

Background: Recommendations on psoriatic arthritis (PsA) state that the target of treatment should be remission or inactive disease. Multiple potential targets have been developed and proposed, each with a different composition of clinical measurements.

Objectives: Our aim is to use an existing real life dataset of a large group of patients in a low disease activity state, to compare different targets and provide further evidence to choose a target.

Methods: This analysis uses data from a cross-sectional real life cohort of 250 PsA patients (EULAR16-2124). All patients were considered in an acceptable disease state according to the treating rheumatologist, defined by the fact that the rheumatologist did not consider to modify the current treatment. Remission/inactive disease targets were the DAPSA [TJC; SJC; patient global visual analogue scale (Pt VAS); pain VAS; CRP] and clinical (c)DAPSA [DAPSA minus CRP] remission $(\leq 4)$, very low disease activity (VLDA) $[7 / 7$ of $T J C \leq 1$; $\mathrm{SJC} \leq 1 ; \mathrm{PASI} \leq 1 ; \mathrm{Pt}$ pain $\leq 15 \mathrm{~mm} ; \mathrm{Pt}$ VAS $\leq 20 \mathrm{~mm} ; \mathrm{HAQ} \leq 0.5$; tender entheseal points $\leq 1$, and PASDAS $\leq 1.9$ or near remission (NR).

Results: 113 pts were in CDAPSA remission, 107 in DAPSA remission, 56 met VLDA and 37 in PASDAS NR. There was a very high percentage exact agreement between DAPSA and CDAPSA (96\%) reflecting the similarity of the two definitions. DAPSA/CDAPSA and VLDA show a high correlation (pearson of 0,611 and 0,590 resp) but VLDA is more stringent in comparison with both DAPSA scores. The correlation between NR and DAPSA/cDAPSA/VLDA was lower, (pearson 0,400, 0,403 and 0,412 resp). Again PASDAS NR was generally more stringent than DAPSA/cDAPSA remission but greater dissimilarities are seen between PASDAS NR and VLDA where 14 patients are in VLDA but not PASDAS NR and 29 are in PASDAS NR but not VLDA.

Although presence of active joint disease was similar across the different measures, VLDA presents as a more stringent cutoff with less residual disease in PASI, TJC and less impact on DLQI and HAQ. All targets had similar \% of patients 